\title{
Value of $\beta$-D-glucan and Candida albicans germ tube antibody for discriminating between Candida colonization and invasive candidiasis in patients with severe abdominal conditions
}

Received: 17 December 2011

Accepted: 27 May 2012

Published online: 30 June 2012

(C) Copyright jointly held by Springer and ESICM 2012

On behalf of the CAVA II Study Group.

The members of the CAVA II Study Group are given in the Appendix.

In memory of Prof. José Pontón, who described the CAGTA technique.

Presented in part at the 24th Annual Congress of the European Society of Intensive Care Medicine, Berlin, Germany, 1-5 October 2011.

Electronic supplementary material The online version of this article (doi:10.1007/s00134-012-2616-y) contains supplementary material, which is available to authorized users.

C. León $(\bowtie) \cdot A$ A Úbeda · A. Loza Intensive Care Unit, Hospital Universitario de Valme, Universidad de Sevilla, Carretera de Cádiz s/n, 41014 Seville, Spain e-mail: cleong@telefonica.net

Tel.: +34-95-5015593

Fax: +34-95-5015594

A. Úbeda

e-mail: alejandroubedaintensivo@ hotmail.com

A. Loza

e-mail: aloza@telefonica.net

\section{S. Ruiz-Santana $\cdot$ O. Fariñas}

Intensive Care Unit, Hospital Universitario Dr. Negrín, Universidad de Las Palmas de Gran Canaria, Las Palmas de Gran Canaria, Spain

e-mail: sergio.ruizsantana@ gobiernodecanarias.org
O. Fariñas

e-mail: ofarinas@hotmail.com

P. Saavedra

Mathematics Department, Universidad de

Las Palmas de Gran Canaria, Las Palmas de Gran Canaria, Spain

e-mail: saavedra@dma.ulpgc.es

C. Castro - E. Martín-Mazuelos Service of Clinical Microbiology, Hospital Universitario de Valme, Universidad de Sevilla, Seville, Spain e-mail: carmencmendez@ hotmail.com

E. Martín-Mazuelos e-mail: estrella.martin.sspa@ juntadeandalucia.es

A. Blanco

Intensive Care Unit, Hospital Universitario Central de Asturias, Oviedo, Spain e-mail: armando.blanco@sespa.princast.es

V. Jerez

Intensive Care Unit, Hospital Infanta

Cristina, Badajoz, Spain

e-mail: v.jerez@telefonica.net

\section{J. Ballús}

Intensive Care Unit, Hospital Universitari de Bellvitge, L'Hospitalet de Llobregat,

Barcelona, Spain

e-mail: 25449jbn@comb.cat

L. Álvarez-Rocha

Intensive Care Unit, Complejo Hospitalario Universitario A Coruña, A Coruña, Spain e-mail: lalvrocha@canalejo.org

A. Utande-Vázquez

Intensive Care Unit, Hospital Universitario Miguel Servet, Zaragoza, Spain e-mail: aranchaut@hotmail.com
Abstract Purpose: To assess the value of ( $1 \rightarrow 3$ )- $\beta$-D-glucan (BDG), Candida albicans germ tube antibody (CAGTA), C-reactive protein (CRP), and procalcitonin (PCT) levels for the diagnosis of invasive candidiasis (IC) and for differentiating Candida spp. colonization from infection in ICU patients with severe abdominal conditions (SAC). Methods: Prospective study of 176 nonneutropenic patients, with SAC at ICU admission, and expected to stay at least 7 days. Surveillance cultures and BDG, CAGTA, CRP, and PCT levels were performed on the third day of ICU stay and twice a week for four consecutive weeks. Patients were grouped into invasive candidiasis (IC), Candida colonization, and neither colonized/nor infected. The classification and regression tree (CART) analysis was used to predict IC in colonized patients. The discriminatory ability of the obtained prediction rule was assessed by the area under the ROC curve (AUC). Results: The probabilities of IC were $59.3 \%$ for the terminal node of BDG greater than $259 \mathrm{pg} / \mathrm{mL}$ and $30.8 \%$ for BDG less than $259 \mathrm{pg} / \mathrm{mL}$ and CAGTA positivity, whereas there was a $93.9 \%$ probability in predicting the absence of IC for BDG less than $259 \mathrm{pg} / \mathrm{mL}$ and negative CAGTA. Using a cutoff of $30 \%$ for IC probability, the prediction rule showed $90.3 \%$ sensitivity, $54.8 \%$ 
specificity, $42.4 \%$ positive predictive value, and $93.9 \%$ negative predictive value with an AUC of 0.78 (95\% confidence interval 0.76-0.81). Significant differences in CRP $(p=0.411)$ and PCT $(p=0.179)$ among the studied groups were not found. Conclusions: BDG with a positive test for CAGTA accurately differentiated Candida colonization from IC in patients with SAC, whereas CRP and PCT did not.
Keywords $(1 \rightarrow 3)-\beta$-D-Glucan Candida albicans germ tube antibody (CAGTA) - C-reactive protein . Procalcitonin - Critically ill patients . Abdominal conditions

\section{Introduction}

The diagnosis of invasive candidiasis (IC) in patients admitted to the ICU still poses a challenge [1]. Clinical prediction rules are relevant elements enabling proper diagnosis but some of them are not easy to fulfill, have not been previously validated, or may be eventually unhelpful in patients having abdominal surgery (e.g., the Candida score) [2-5]. Specific antigen components of the fungal cell wall have been exploited for the development of diagnostic assays that can detect the presence of these components in the serum. An important component of the cell wall of the majority of fungi is $(1 \rightarrow 3)$ - $\beta$-D-glucan (BDG). Although the test is not Candida specific, it has been found to be a promising tool to diagnose invasive fungal infections, most of them being IC [6]. The accuracy of BDG for the diagnosis of invasive fungal infections has been discussed in a recent meta-analysis [7]. Also, a test based on the detection of antibodies against the surface of $C$. albicans germ tubes (CAGTA) has been commercialized [8]. Two newly published studies showed a significant decrease in mortality in ICU patients with a CAGTA-positive result especially in those with increasing CAGTA values who had been treated with antifungals [9, 10]. C-reactive protein (CRP) [11] and procalcitonin (PCT) $[12,13]$ have been also reported to be valuable markers.

The efficiency of diagnostic biomarkers in the field of fungal infections has become the object of intensive investigation. The aim of this study was to explore the accuracy of the following biomarkers: BDG, CAGTA, CRP, PCT, and some of them combined, for discriminating between Candida spp. colonization and IC in non-neutropenic critically ill patients with severe abdominal conditions (SAC) and to establish a model for the prediction of IC.

\section{Patients and methods}

Design and setting

This was a prospective, cohort, observational, and multicenter study conducted in the ICU setting in routine clinical practice. The study protocol was approved by the ethics committees of the participating centers, and informed consent was obtained from the patients or their representatives.

Study population

All patients older than 18 years with SAC on ICU admission who were admitted to 18 medical-surgical ICUs of tertiary care hospitals in Spain between 1 April 2009 and 30 June 2010 were eligible. To be included in the study, an expected ICU stay of at least 7 days was required. At ICU entry, patients with neutropenia (total leukocyte count less than $1,000 / \mathrm{mm}^{3}$ ) were excluded as were those with other conditions (see Supplementary Material).

Screening, microbiological cultures, and Candida score

Surveillance cultures for Candida spp. were performed using samples obtained from feces (or rectal swabs), urine, skin (axillary surface), tracheal aspirates (or protected specimen brush or bronchoalveolar lavage), gastric or pharyngeal aspirates, and the peripheral blood. Other samples from the peripheral blood, vascular lines, wound/ drainage exudates, or infected foci were obtained at the discretion of the attending physician. (See Supplementary Material for details of microbiological cultures). Results were considered positive in the presence of Candida growth in the culture medium. The different Candida isolates were identified at species level. As soon as the results of surveillance cultures were available and at the time of starting antifungal treatment in patients with IC, the Candida score (CS) was calculated [4], with a cutoff point of at least 3 for discriminating between Candida spp. colonization and IC.

\section{Serological biomarkers}

Reference values for the serological tests were $80 \mathrm{pg} / \mathrm{mL}$ for the BDG assay, at least 1/160 for positive CAGTA, 0-5 mg/dL for CRP, and $0.5 \mathrm{ng} / \mathrm{mL}$ for PCT. Technical details of these assays are described in the Supplementary Material. 
For each patient, maximum values recorded for Candida score and serologic biomarkers at or before the episode of IC were used in the analysis. When an episode of IC did not develop, the highest value of all observed values was used.

\section{Definitions}

A SAC was defined as the process that caused gastrointestinal dysfunction or failure in the context of a medicalsurgical abdominal illness, including nonsurgical diseases (e.g., pancreatitis), emergency or elective surgical procedures, and related complications (e.g., gastrointestinal perforation, hepatobiliary and pancreatic disorders, peritonitis, intra-abdominal abscess, anastomotic leak), and prolonged postoperative stay after complicated abdominal surgery.

Candida colonization was considered unifocal when Candida spp. was isolated from one site and multifocal when Candida spp. was simultaneously isolated from various noncontiguous sites, even if two different Candida spp. were isolated [14, 15].

The diagnosis of IC required one of the following criteria: presence of candidemia, i.e., documentation of one or more blood culture(s) that yielded a Candida spp. in a patient with consistent clinical manifestations, isolation of Candida spp. from a normally sterile body fluids (e.g., pleural fluid, pericardial fluid) or candidal peritonitis, ophthalmic examination consistent with candidal endophthalmitis in a patient with clinical sepsis, or histologically documented candidiasis. IC was also considered if histopathological examination revealed typical patterns, such as pseudohyphae or true hyphae, in a relevant clinical context [16]. The definitions of candidal peritonitis [17], candidal endophthalmitis [18], catheterrelated candidemia [19], and candiduria are described in the Supplementary Material.

Patients were classified into the groups of neither colonized nor infected, Candida spp. colonization without IC, and IC. Otherwise, the decision to treat a patient with antifungal drugs was left to the investigators' discretion.

\section{Study protocol and collection of data}

Once the patient was included in the study, the following data were recorded on the third day of ICU stay and twice a week thereafter for four consecutive weeks until ICU discharge or death: APACHE II score, SOFA score, surveillance cultures, Candida score, and presence or absence of sepsis, severe sepsis, or septic shock. Blood samples for the measurement of BDG, CAGTA, CRP, and PCT were drawn at the same time periods. Patients were followed until ICU and/or hospital discharge, or death. Other variables recorded are detailed in the Supplementary Material.

\section{Sample size and statistical analysis}

In a previous study [4], BDG was assessed in 65 of 217 non-neutropenic critically ill patients who underwent abdominal operations, yielding 11 patients classified into the neither colonized nor infected group, 45 into the Candida spp. colonization group, and 9 into the IC group. The area under the receiver operating characteristics (ROC) curve to assess the discriminatory power of BDG to distinguish Candida spp. colonization from IC was 0.731 [95\% confidence interval (CI) 0.620-0.841]. According to these results, 38 patients would be required in the IC group and 95 in the Candida spp. colonization group to estimate the area under the ROC curve (AUC) with an error bound of $10 \%$ corresponding to the BDG.

Categorical variables are expressed as frequencies and percentages, and continuous variables as mean and standard deviation (SD) when data followed a normal distribution, or as median and interquartile (25th-75th percentile) range (IQR) when distribution departed from normality. The percentages were compared using the Chisquare $\left(\chi^{2}\right)$ test, the means by the $F$ test, and the medians by the Kruskal-Wallis test. In patients with fungal colonization, a model for the prediction of the IC was obtained using the classification and regression trees (CART) procedure [20]. CART classifies data using a sequence of if-then rules. The basis of the decision tree algorithms is the binary recursive partitioning of the data. The most discriminative variable is first selected to partition the data set into child nodes. The splitting continues until some stopping criterion is reached. At each terminal node, the probability of IC was estimated as the proportion of patients belonging to that node that developed the event. The tree was constructed according to the following algorithm: in the first stage, the tree grows until all cases are correctly classified, and in the second stage, we used the tenfold cross-validation method of successive pruning [20]. Finally, the tree that minimized the error measurement (deviance) was chosen. For this predictor the corresponding ROC curve was obtained and the AUC was estimated by means of a $95 \% \mathrm{CI}$. The predictive rule identified that a patient had an IC risk when the probability to develop the IC was $30 \%$ or above. Sensitivity, specificity, and predictive values of the prediction rule were calculated. The data analysis was carried out using the R-package.

\section{Results}

Study population and salient findings

Of the initial 338 eligible patients, 162 were excluded because of lack of fulfillment of the inclusion criteria, incomplete clinical data collection, or blood samples to 
determine biologic biomarkers were not drawn (Fig. 1). The study population consisted of 176 patients, $65.9 \%$ men, with a mean age (SD) of 64.1 (15.0) years. The mean (SD) APACHE II score and SOFA score on ICU admission was 18.7 (6.1) and 7.4 (3.6), respectively. The reason for ICU admission was medical in $18.8 \%$ of patients, surgical in $76.1 \%$, and trauma in $5.1 \%$. The median (IQR) length of ICU and hospital stay was 15 (10-27) and 38 (24-57) days, respectively, which were significantly higher in patients with IC compared to the other two groups. ICU and hospital crude mortality rates were 26.7 and $32.4 \%$, respectively.

Abdominal conditions were gastrointestinal perforation (small and large intestine) 50 (28.4\%), prolonged postoperative state after complicated abdominal surgery (e.g., postoperative scheduled gastrointestinal neoplasia, intestinal ischemia, etc.) $47(26.7 \%)$, pancreatitis (no surgical) $32(18.1 \%)$, hepatobiliary-pancreatic pathology (cholecystitis/gallbladder perforation, liver abscess, pancreatic/peripancreatic abscesses) 25 (14.2\%), anastomotic leakage (esophagus, small and large intestine) 14 $(7.9 \%)$, and peritonitis with interbowel abscesses 8 $(4.5 \%)$.

There were 61 patients in the neither colonized nor infected group, 84 in the Candida spp. colonization group, and 31 in the IC group. Table 1 provides the clinical characteristics of the participants. The rate of emergency surgery was significantly higher $(p<0.001)$ in the IC group than in the remaining two groups. Patients in the IC group showed significant differences as compared with the remaining groups in the maximum APACHE II and SOFA scores before or during the IC event, the Candida score, and the length of ICU stay and hospital stay. Data of the 31 patients with IC are summarized in Table 2. Most cases of IC were detected in the second week of ICU stay. Twenty-one of them had previous multifocal colonization, with a median of 3 days between colonization and IC (IQR 0-9).

\section{Serological biomarkers and Candida score}

A total of 766 blood samples (median 3, IQR 2-6) were drawn for the measurement of serological biomarkers. In the first study control on the third day after ICU admission, only the CS was significantly different in the IC group as compared with the other two groups. However, when the maximum values and rates were considered, BDG and CAGTA in addition to CS were also significantly different (Table 3). In relation to the influence of antifungal treatment on serological biomarkers, the median value of the variation between pre-treatment and
Fig. 1 Flow chart of this study population

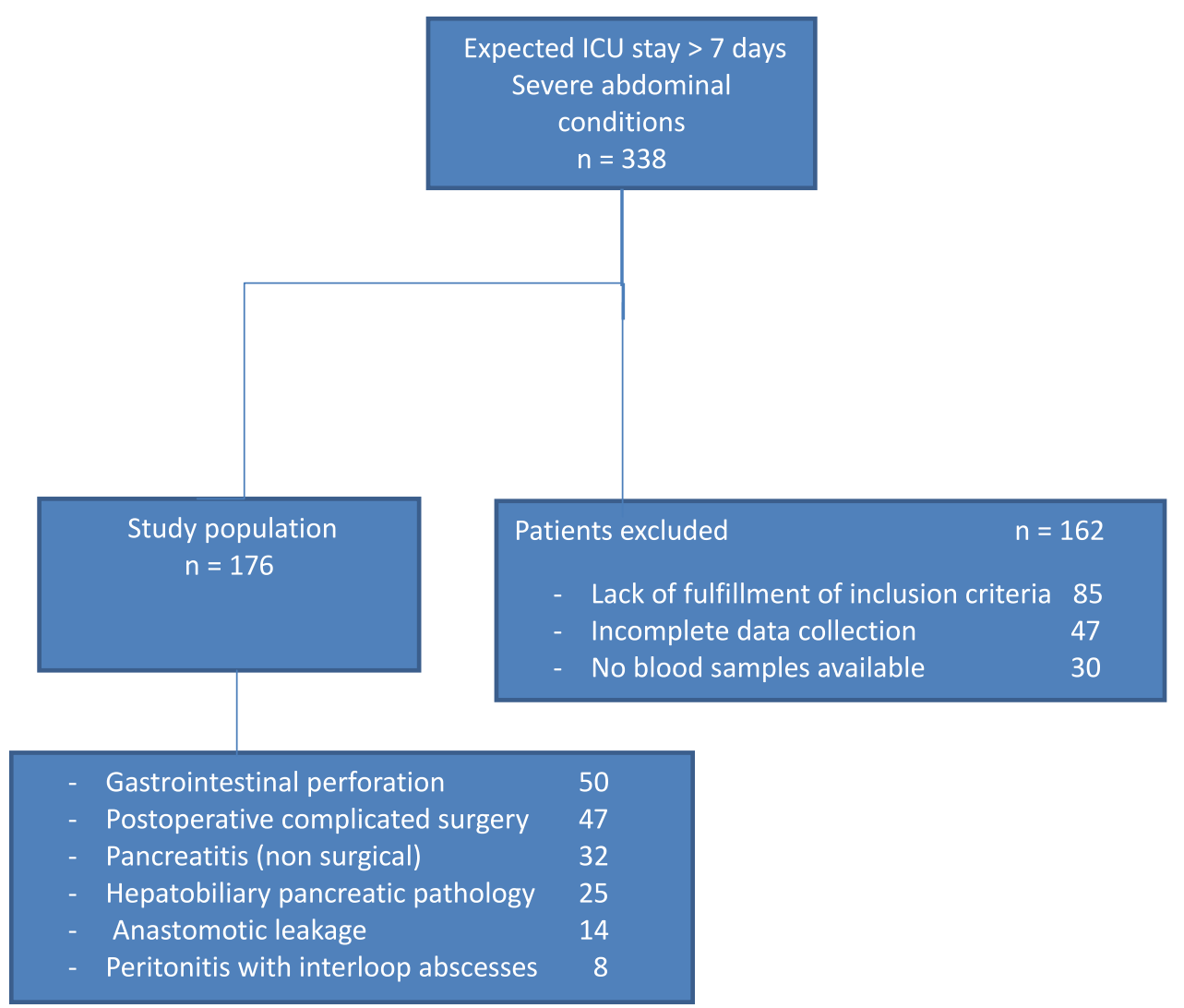


Table 1 Characteristics of the study patients according to colonization and infection status

\begin{tabular}{|c|c|c|c|c|c|}
\hline & \multirow{2}{*}{$\begin{array}{l}\text { All patients } \\
(n=176)\end{array}$} & \multicolumn{3}{|l|}{ Study groups } & \multirow[t]{2}{*}{$P$ value } \\
\hline & & $\begin{array}{l}\text { Neither } \\
\text { colonized } \\
\text { nor infected } \\
(n=61)\end{array}$ & $\begin{array}{l}\text { Candida spp. } \\
\text { colonization } \\
(n=84)\end{array}$ & $\begin{array}{l}\text { Invasive } \\
\text { candidiasis } \\
(n=31)\end{array}$ & \\
\hline Age, years, mean $( \pm S D)$ & $64.1 \pm 15.0$ & $60.2 \pm 15.6$ & $66.2 \pm 15.1$ & $65.8 \pm 12.4$ & 0.046 \\
\hline Male/female $(\%)$ & $65.9 / 34.1$ & $73.8 / 26.2$ & $61.9 / 38.1$ & $61.3 / 38.7$ & 0.276 \\
\hline \multicolumn{6}{|l|}{ APACHE II score, mean $( \pm S D)$} \\
\hline ICU admission & $18.7 \pm 6.1$ & $17.9 \pm 5.4$ & $18.6 \pm 6.1$ & $20.4 \pm 7.4$ & 0.161 \\
\hline Maximum before/during development & $17.7 \pm 6.5$ & $16.1 \pm 6.6$ & $17.7 \pm 6.5$ & $20.6 \pm 5.7$ & 0.007 \\
\hline \multicolumn{6}{|l|}{ SOFA score, mean $( \pm \mathrm{SD})$} \\
\hline ICU admission & $7.4 \pm 3.6$ & $7.1 \pm 3.7$ & $7.3 \pm 3.6$ & $8.2 \pm 3.7$ & 0.428 \\
\hline Maximum before/during development & $7.5 \pm 4.0$ & $6.8 \pm 4.1$ & $7.4 \pm 4.0$ & $9.2 \pm 3.6$ & 0.024 \\
\hline $\begin{array}{l}\text { Maximum CS before/during development } \\
\text { IC, median (IQR) }\end{array}$ & $4(2-4)$ & $2(2-4)$ & $4(3-5)$ & $5(3-5)$ & $<0.001$ \\
\hline ICU length of stay, days, median (IQR) & $15(10-27)$ & $11(9-20)$ & $15(10-23)$ & $32(21-45)$ & $<0.001$ \\
\hline Hospital length of stay, days, median (IQR) & $38(24-57)$ & $31(20-47)$ & $38(26-62)$ & $52(34-73)$ & 0.005 \\
\hline ICU mortality, no. (\%) & $47(26.7)$ & $15(24.6)$ & $19(22.6)$ & $13(41.9)$ & 0.104 \\
\hline Overall mortality, no. (\%) & $57(32.4)$ & $17(27.9)$ & $27(32.1)$ & $13(41.9)$ & 0.394 \\
\hline \multicolumn{5}{|l|}{ Types of patients on ICU admission, no. (\%) } & 0.068 \\
\hline Medical & $33(18.8)$ & $16(26.2)$ & $15(17.9)$ & $2(6.5)$ & \\
\hline Surgical & $134(76.1)$ & $44(72.1)$ & $62(73.8)$ & $28(90.3)$ & \\
\hline Trauma & $9(5.1)$ & $1(1.6)$ & $7(8.3)$ & $1(3.2)$ & \\
\hline Total multifocality, no. (\%) & $111(96.5)$ & - & $83(98.8)$ & $28(90.3)$ & $0.059 *$ \\
\hline \multicolumn{5}{|l|}{$\begin{array}{l}\text { Clinical condition at the second week } \\
\text { of ICU stays, no. (\%) }\end{array}$} & 0.258 \\
\hline No sepsis & $44(25.0)$ & $15(24.6)$ & $22(26.2)$ & $7(22.6)$ & \\
\hline Sepsis & $49(27.8)$ & $21(34.4)$ & $24(28.6)$ & $4(12.9)$ & \\
\hline Severe sepsis & $39(22.2)$ & $9(14.8)$ & $20(23.8)$ & $10(32.3)$ & \\
\hline Septic shock & $44(25.0)$ & $16(26.2)$ & $18(21.4)$ & $10(32.3)$ & \\
\hline \multicolumn{6}{|l|}{ Diagnosis on admission, no. (\%) } \\
\hline Postoperative emergency gastrointestinal surgery & $91(51.7)$ & $29(47.5)$ & $40(47.6)$ & $22(71.0)$ & 0.061 \\
\hline Postoperative elective gastrointestinal surgery & $22(12.5)$ & $10(16.4)$ & $11(13.1)$ & $1(3.2)$ & 0.191 \\
\hline Mesenteric infarction & $3(1.7)$ & $1(1.6)$ & $1(1.2)$ & $1(3.2)$ & 0.755 \\
\hline Peritonitis & $48(27.3)$ & 17 (27.9) & $21(25.0)$ & $10(30.2)$ & 0.734 \\
\hline Pancreatitis & $39(22.2)$ & $17(27.9)$ & $17(20.2)$ & $5(16.1)$ & 0.370 \\
\hline \multicolumn{5}{|l|}{ Surgery (characteristics), no. (\%) } & 0.001 \\
\hline No surgery & $22(12.5)$ & $13(21.3)$ & $9(10.7)$ & 0 & \\
\hline Emergency & $128(72.7)$ & 39 (63.9) & $58(69.0)$ & $31(100)$ & \\
\hline Elective & $26(14.8)$ & $9(14.8)$ & $17(20.2)$ & 0 & \\
\hline Abdominal surgery, no. (\%) & $144(82.3)$ & 48 (78.6) & $68(81.9)$ & $28(90.3)$ & 0.382 \\
\hline \multicolumn{5}{|l|}{ Surgical procedures, no. $(\%)$} & 0.004 \\
\hline None & $22(12.6)$ & $13(21.7)$ & $9(10.8)$ & 0 & \\
\hline One & $77(44.3)$ & $25(41.7)$ & $42(50.6)$ & $10(32.3)$ & \\
\hline Two or more & $75(43.1)$ & $22(36.7)$ & $32(38.6)$ & $2167.7)$ & \\
\hline \multicolumn{6}{|l|}{ Underlying illnesses, no. (\%) } \\
\hline Diabetes mellitus & $41(23.3)$ & $14(23.0)$ & $23(27.4)$ & $4(12.9)$ & 0.264 \\
\hline Chronic liver failure & $12(6.8)$ & $5(8.2)$ & $5(6.0)$ & $2(6.5)$ & 0.866 \\
\hline Hematologic malignancy & $3(1.7)$ & 0 & $1(1.2)$ & $2(6.5)$ & 0.069 \\
\hline Chronic renal failure & $17(9.7)$ & $4(6.6)$ & $9(10.7)$ & $4(12.9)$ & 0.562 \\
\hline Heart failure (NYHA, class III, IV) & $6(3.4)$ & $2(3.3)$ & $3(3.6)$ & $1(3.2)$ & 0.994 \\
\hline Solid tumor & $35(19.9)$ & $9(14.8)$ & $23(27.4)$ & $3(9.7)$ & 0.050 \\
\hline Chronic obstructive pulmonary disease & $30(17.0)$ & $12(19.7)$ & $13(15.5)$ & $5(16.1)$ & 0.794 \\
\hline Alcoholism & $30(17.0)$ & $15(24.6)$ & $11(13.1)$ & $4(12.9)$ & 0.153 \\
\hline \multicolumn{6}{|l|}{ Risk factors, no. (\%) } \\
\hline Urinary catheter & $173(98.3)$ & $61(100)$ & $82(97.6)$ & $30(96.8)$ & 0.424 \\
\hline Central venous catheter & $176(100)$ & $61(100)$ & $84(100)$ & $31(100)$ & \\
\hline Mechanical ventilation & $151(85.8)$ & $51(83.6)$ & $71(84.5)$ & $29(93.5)$ & 0.391 \\
\hline Broad spectrum antibiotics & $172(97.7)$ & $60(98.4)$ & $82(97.6)$ & $30(96.8)$ & 0.886 \\
\hline Arterial catheter & $148(84.1)$ & $51(83.9)$ & $71(84.5)$ & $26(83.9)$ & 0.988 \\
\hline Enteral nutrition & $76(43.2)$ & $20(32.8)$ & $39(46.4)$ & $17(54.8)$ & 0.092 \\
\hline Total parenteral nutrition & $166(94.3)$ & $56(91.8)$ & $80(95.2)$ & $30(96.8)$ & 0.548 \\
\hline
\end{tabular}


Table 1 continued

\begin{tabular}{|c|c|c|c|c|c|}
\hline & \multirow{2}{*}{$\begin{array}{l}\text { All patients } \\
(n=176)\end{array}$} & \multicolumn{3}{|l|}{ Study groups } & \multirow[t]{2}{*}{$P$ value } \\
\hline & & $\begin{array}{l}\text { Neither } \\
\text { colonized } \\
\text { nor infected } \\
(n=61)\end{array}$ & $\begin{array}{l}\text { Candida spp. } \\
\text { colonization } \\
(n=84)\end{array}$ & $\begin{array}{l}\text { Invasive } \\
\text { candidiasis } \\
(n=31)\end{array}$ & \\
\hline Corticosteroids & $74(42.0)$ & $21(34.4)$ & $38(45.2)$ & $15(48.4)$ & 0.314 \\
\hline Renal replacement therapy & $45(25.6)$ & $13(21.3)$ & $20(23.8)$ & $12(38.7)$ & 0.171 \\
\hline $\begin{array}{l}\text { Selective digestive decontamination } \\
\text { (no antifungal drugs) }\end{array}$ & $37(21.0)$ & $11(18.0)$ & $19(22.6)$ & $7(22.6)$ & 0.778 \\
\hline Antifungal treatment & $53(30.1)$ & $4(6.6)$ & $21(25.0)$ & $28(90.3)$ & $<0.001$ \\
\hline
\end{tabular}

ICU intensive care unit, IC invasive candidiasis, APACHE II Acute Physiology and Chronic Health Evaluation, CS Candida score, SOFA Sequential Organ Failure Assessment, GI gastrointestinal, NYHA New York Heart Association

* Colonized versus IC groups; median (25th-75th percentiles)

Table 2 Characteristics of the 31 patients with invasive candidiasis (IC)

\begin{tabular}{ll}
\hline & No. patients \\
\hline Abdominal conditions & \\
Gastroduodenal perforation & 9 \\
Pancreatitis & 5 \\
Intestinal perforation (large intestine) & 5 \\
Cholecystitis & 3 \\
Peritonitis with interloop abscesses & 3 \\
Anastomotic leakage & 3 \\
Postoperative complex complicated & 2 \\
abdominal surgery & 1 \\
Liver abscess & 28 \\
Multifocal Candida spp. colonization & $7(22.6 \%)$ \\
Candidemia & 2 \\
Catheter-related candidemia & $23(74.2 \%)$ \\
Candidal peritonitis & $1(3.8 \%)$ \\
Candidemia and candidal peritonitis & \\
Causative Candida spp. & 15 \\
C. albicans & 6 \\
C. tropicalis & 7 \\
C. glabrata & 1 \\
C. krusei & 1 \\
C. lusitanie & 1 \\
C. albicans + C. glabrata & $9(5-20)$ \\
Time between ICU admission and & \\
IC diagnosis, days, median (IQR) & $13(10-22)$ \\
Patients with candidemia & $7(4-17)$ \\
Patients with candidal peritonitis & 28 \\
Antifungal treatment & 10 \\
Azoles & 8 \\
Echinocandins & 10 \\
Combination of 2 or 3 antifungals & \\
(second choice therapy) & \\
\hline
\end{tabular}

$I C U$ intensive care unit, IQR interquartile (25th-75th percentile) range

post-treatment levels was zero for CAGTA and 0 (IQR -37 ; 31) for BDG. Also, serum levels of CRP and PCT were similar in the three study groups (Table 3 ).

\section{CART predictive model}

The CART decision tree model showed a probability of IC of $59.3 \%$ in the terminal node of BDG with levels greater than $259 \mathrm{pg} / \mathrm{mL}$ and a probability of $30.8 \%$ for the combination of BDG less than $259 \mathrm{pg} / \mathrm{mL}$ and CAGTA positive results. In the presence of BDG levels less than $259 \mathrm{pg} / \mathrm{mL}$ and CAGTA negative results, the probability of having IC was only $6.1 \%$ (Fig. 2). Using a cutoff of $30 \%$ for the probability of IC, chosen by the CART algorithm to minimize the deviance, the resulting prediction rule showed a $90.3 \%$ sensitivity, $54.8 \%$ specificity, $42.4 \%$ positive predictive value, and $93.9 \%$ negative predictive value. This prediction rule was better than for the individual analysis of BDG, CAGTA, and CS (Table 4). The AUC of the ROC curve was 0.78 (95\% CI 0.76-0.81). However, a cutoff point of serum BDG of $80 \mathrm{pg} / \mathrm{mL}$ showed much worse predictive values with $67.7 \%$ sensitivity, $54.7 \%$ specificity, $35.5 \%$ positive predictive value, and $82.1 \%$ negative predictive value. The total number of patients with Candida spp. colonization was 115 . The number of patients that would have received unnecessary antifungal treatment (false positives) was $38(33.3 \%)$. However, among the 31 patients with IC, there were only three false negatives. Table 5 shows the application of the CART-derived prediction rule.

\section{Discussion}

The combination of two biomarkers, BDG and CAGTA, allowed a novel structured diagnostic approach to IC in patients with SAC. This finding is clinically relevant not only for the population to which the prediction rule can be applied, but also because it is very easy to remember and may help intensivists to decide when to start antifungal treatment. 
Table 3 Candida score and serological biomarkers in the first control and maximum values before or during the development of invasive candidiasis or the highest value when invasive candidiasis did not develop

\begin{tabular}{|c|c|c|c|c|c|}
\hline & Assessment & $\begin{array}{l}\text { Neither colonized } \\
\text { nor infected }(n=61)\end{array}$ & $\begin{array}{l}\text { Candida spp. } \\
\text { colonization }(n=84)\end{array}$ & $\begin{array}{l}\text { Invasive candidiasis } \\
(n=31)\end{array}$ & $P$ value \\
\hline \multirow[t]{2}{*}{ Candida score } & $1 \mathrm{st}$ & $2(2-4)$ & $3(2-4)$ & $4(2-5)$ & $<0.001$ \\
\hline & Max. & $2(2-4)$ & $4(3-5)$ & $5(3-5)$ & $<0.001$ \\
\hline \multirow[t]{2}{*}{$(1 \rightarrow 3)$ - $\beta$-D-glucan $(\mathrm{pg} / \mathrm{mL})$} & $1 \mathrm{st}$ & $9(9-91)$ & $45(9-152)$ & $54(9-350)$ & 0.110 \\
\hline & Max. & $52(9-145)^{\mathrm{a}}$ & $66(21-168)^{\mathrm{a}}$ & $268(50-444)^{\mathrm{b}}$ & 0.003 \\
\hline \multirow[t]{2}{*}{ CAGTA (\%) } & $1 \mathrm{st}$ & 25.0 & 25.0 & 43.3 & 0.129 \\
\hline & Max. & $39.3^{\mathrm{a}}$ & $41.7^{\mathrm{a}}$ & $71.0^{\mathrm{b}}$ & 0.009 \\
\hline \multirow[t]{2}{*}{ C-reactive protein $(\mathrm{mg} / \mathrm{L})$} & $1 \mathrm{st}$ & $201(103-334)$ & $207(99-335)$ & $172(107-282)$ & 0.911 \\
\hline & Max. & $248(142-373)$ & $241(125-383)$ & $283(177-426)$ & 0.411 \\
\hline \multirow[t]{2}{*}{ Procalcitonin (ng/mL) } & $1 \mathrm{st}$ & $0.89(0.2-3.21)$ & $0.58(0.23-5.48)$ & $1.11(0.29-6.14)$ & 0.590 \\
\hline & Max. & $1.25(0.33-5.0)$ & $0.59(0.3-7.14)$ & $3.33(0.74-6.34$ & 0.179 \\
\hline
\end{tabular}

Values are medians and interquartile range $\left(25\right.$ th -75 th percentile) ${ }^{\text {a,b }}$ Superscripts indicate significant differences $(P<0.05)$ among CAGTA Candida albicans germ tube antibodies, $1 s t$ first control, rates of BDG and positive CAGTA values among the three study Max maximum value before or during invasive candidiasis (when groups invasive candidiasis did not develop, the highest of all observed values was recorded)

Fig. 2 Prediction rule for the diagnosis of invasive candidiasis (IC) in nonneutropenic adult critically ill patients with severe abdominal conditions. Each terminal node shows the probability of the predicted event

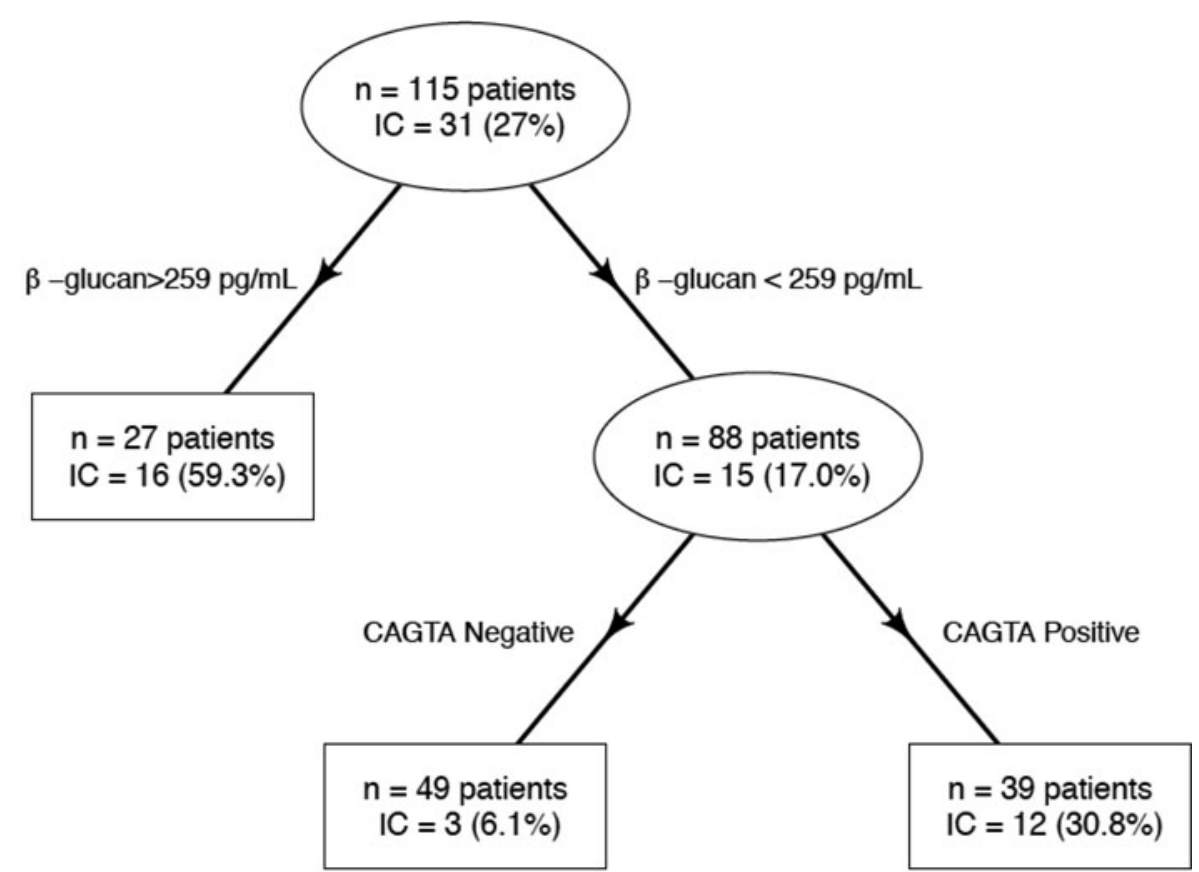

IC: invasive candidiasis.

BDG: $[1 \rightarrow 3]-\beta-D-$ glucan;

CAGTA: Candida albicans germ tube antibodies.

$\mathrm{n}=$ number of patients with IC.

A few studies have investigated the predictive value of Pneumocystis jirovecii infections [26], Gram-positive and BDG on IC in non-neutropenic critically ill patients Gram-negative bloodstream infections, exposure to gauze [21-25]. Elevated concentrations of BDG have been or other materials that contain glucans, biofilms on vasreported to be associated with other fungi, such as cular catheters, hemodialysis, and administration of 
Table 4 Diagnostic accuracy of CART-derived prediction rule, BDG (cutoff, $>259 \mathrm{pg} / \mathrm{mL}$ ), CAGTA (cutoff, any positive value), and CS for the diagnosis of invasive candidiasis

\begin{tabular}{|c|c|c|c|c|c|}
\hline & \multirow{2}{*}{$\begin{array}{l}\text { Area under ROC } \\
\text { curve }(95 \% \mathrm{CI})^{\mathrm{a}}\end{array}$} & \multirow{2}{*}{$\begin{array}{l}\text { Sensitivity \% } \\
(95 \% \mathrm{CI})\end{array}$} & \multirow{2}{*}{$\begin{array}{l}\text { Specificity \% } \\
(95 \% \text { CI })\end{array}$} & \multicolumn{2}{|l|}{ Predictive value } \\
\hline & & & & $\begin{array}{l}\text { Positive \% } \\
(95 \% \mathrm{CI})\end{array}$ & $\begin{array}{l}\text { Negative \% } \\
(95 \% \mathrm{CI})\end{array}$ \\
\hline CART analysis & $0.78(0.76-0.81)$ & $90.3(75.1-96.6)$ & $54.8(44.1-65.0)$ & $42.4(31.2-54.4)$ & $93.9(83.5-97.9)$ \\
\hline BDG & $0.66(0.59-0.74)$ & $51.6(34.8-68.0)$ & $86.9(78.0-92.5)$ & $59.3(40.7-75.5)$ & $83.0(73.8-89.4)$ \\
\hline CAGTA & $0.67(0.64-0.71)$ & $71.0(53.4-83.9)$ & $57.3(46.5-67.5)$ & $38.6(27.1-51.6)$ & $83.9(72.2-91.3)$ \\
\hline CS & $0.62(0.58-0.66)$ & $93.5(79.2-98.2)$ & $18.1(11.3-27.7)$ & $29.9(21.7-39.6)$ & $88.2(65.7-96.7)$ \\
\hline
\end{tabular}

Total number of patients with Candida spp. colonization $=115$

CART classification and regression tree analysis, BDG beta-D-glucan, CAGTA Candida albicans germ tube antibody, CS Candida score

a Original scale

Table 5 CART-derived prediction rule applied for all the study population

\begin{tabular}{lllr}
\hline & $\begin{array}{l}\text { Node BDG }<259 \\
\text { and CAGTA negative }\end{array}$ & $\begin{array}{l}\text { Node BDG }<259 \\
\text { and CAGTA positive }\end{array}$ & BDG $>259$ \\
\hline Neither colonized nor infected, $n(\%)$ & $31(50.8)$ & $18(29.5)$ & $12(19.7)$ \\
Candida spp. colonization, $n(\%)$ & $46(54.8)$ & $27(32.1)$ & $11(13.1)$ \\
Invasive candidiasis, $n(\%)$ & $3(9.7)$ & $12(38.7)$ & 81 \\
Total, $n(\%)$ & $80(45.5)$ & $57(32.4)$ & $31.6)$ \\
\hline
\end{tabular}

$C A R T$ classification and regression tree analysis, $B D G$ beta-D-glucan, CAGTA Candida albicans germ tube antibody

intravenous immunoglobulins, albumin, coagulation factors, and plasma protein fractions [27-29]. In addition, Pickering et al. [29] showed in a cross-contamination experiment that excess manipulation of a sample can result in its contamination with BDG. In our IC patients, $12(38.7 \%)$ had renal replacement therapy, $3(9.6 \%)$ had Gram-positive bacteremia, and $3(9.6 \%)$ received betalactam antibiotics. None of them presented Gram-negative bacteremia or received immunoglobulins, albumin, coagulation factor, or plasma protein fractions. However, Candida multifocal colonization was documented in 28 $(90.3 \%)$ of the IC patients and occult candidemia cannot be totally excluded. In a retrospective study performed in patients admitted for 7 or more days to nine ICUs, it has been shown that those patients with IC had mean concentrations of BDG, measured twice weekly, persistently high over time that decreased slowly after approximately 4 weeks [30]. Our results showed that CAGTA and BDG values are apparently not affected by antifungal treatment. We observed that CAGTA and BDG responses after antifungal treatment were quite diverse and this explains why the median value before and after treatment was zero. Although it seems that antifungal use did not impact the performance of BDG [31], biomarker kinetics in this scenario and particularly responses after starting antifungal treatment deserve further investigation.
There are only two previous reports of the same group $[9,10]$ assessing the predictive value of CAGTA for IC in a cohort of 53 critically ill non-neutropenic patients in which CAGTA was measured twice a week. Twenty-two patients $(41.5 \%)$ had CAGTA-positive results and none of them had a positive blood culture for Candida. The authors concluded that CAGTA detection may be important for the diagnosis of IC in ICU surgical patients. This test provides a rapid and quite simple laboratory IC diagnosis with a sensitivity of $84.4 \%$ and a specificity of $94.7 \%$ and it has been claimed to be independent of Candida colonization or antifungal treatment. Although CAGTA is designed for $C$. albicans germ tube antibody detection we also realized that it works for non-albicans species, which is an interesting finding when diagnosing an IC in the critical ill setting.

Although previous studies have shown the usefulness of BDG for the diagnosis of IC in surgical patients [6, 22, 25], our findings confirm that BDG is highly specific for a cutoff value of $259 \mathrm{pg} / \mathrm{mL}$ but with a very low sensitivity $(51.6 \%)$. CAGTA (negative/limit-positive) has a better sensitivity than BDG but its specificity is lower. Our predictive rule based on CART that includes both biomarkers demonstrates a sensitivity of $90.3 \%$, which is greater than the sensitivities found in both biomarkers, and an adequate specificity. When we analyzed the 
dynamics of the most representative cases of both biomarkers, there were 13 cases in which BDG was lower than the cutoff value of $259 \mathrm{pg} / \mathrm{mL}$ and in 11 of them, CAGTA was positive, thus showing the complementariness of both biomarkers expressed by means of the CART analysis.

This study shows that BDG levels greater than $259 \mathrm{pg} /$ $\mathrm{mL}$ combined with CAGTA-positive results accurately discriminate Candida spp. colonization from IC in nonneutropenic critically ill patients with SAC. The predictive rule rests on BDG levels, which is the main node of the tree, and when these levels are greater than $259 \mathrm{pg} /$ $\mathrm{mL}$, the patients have a nearly $60 \%$ probability of having an IC. Moreover, using a cutoff of $30 \%$ for the probability of IC, the CART-derived decision model had a very high negative predictive value, with a $93.9 \%$ probability of not having IC for BDG less than $259 \mathrm{pg} / \mathrm{mL}$ combined with CAGTA-negative results. Other commonly used biomarkers, such as CRP and PCT, were not useful to distinguish between IC and Candida spp. colonization. In agreement with previous studies, the Candida score was significantly higher in patients with IC than in the remaining groups, but the usefulness of this prediction rule is limited in patients undergoing abdominal surgery because in these circumstances the score is consistently higher than the discriminating cutoff point of at least 3 . The CART analysis showed a very high negative predictive value, which is in agreement with data obtained by Ostrosky-Zeichner et al. [3] with their prediction rule as well as with the CS in our two previous studies [2, 4]. However, the CART positive predictive value was $42.4 \%$, which is clearly higher than $9 \%$ obtained by the prediction rule of Ostrosky-Zeichner et al. [3] and $13.8 \%$ with CS in our previous study [4].

In patients admitted to an ICU with SAC if serum BDG levels are over $259 \mathrm{pg} / \mathrm{mL}$ or if BDG levels are lower than $259 \mathrm{pg} / \mathrm{mL}$ but CAGTA levels are positive, the IC risk is 59.3 and $30.8 \%$, respectively. Despite the $42.4 \%$ positive predictive value of the CART model, we think that in this specific scenario clinicians should start AF therapy. This means that for every 100 treated patients, the expected number of overtreated would be 57.6. On the contrary, in similar patients with a BDG level lower than $259 \mathrm{pg} / \mathrm{mL}$ and negative CAGTA limits, no AF treatment should be started owing to the very high negative predictive value shown by the CART analysis even though for every 100 patients with IC, the expected number of untreated patients would be of 9.7.

Potential limitations are as follows: BDG testing was performed in batches or frozen samples and we cannot exclude that some negative results may have stemmed from sample instability. Also, the presence of intestinal mucositis may facilitate the translocation of Candida spp. through the gastrointestinal barrier and eventually might interfere with BDG determinations [24]. Although CAGTA was developed for $C$. albicans detection, it may be also useful for the diagnosis of IC in cases of nonalbicans strains. However, our study population was not sufficiently large for a reliable analysis of the differences between $C$. albicans and non-albicans strains.

In summary, non-neutropenic critically ill patients with SAC at ICU entry and an expected stay of at least 7 days, BDG greater than $259 \mathrm{pg} / \mathrm{mL}$ with a CAGTApositive result accurately differentiated Candida spp. colonization from IC. Further studies are needed to confirm the present data.

Acknowledgments The authors thank Marta Pulido, MD, for editing the manuscript and editorial assistance. This work was supported by a grant from Astellas Pharma, S.A., Madrid, Spain. Astellas Pharma, S.A., had no role in the collection, analysis, or interpretation of data or in the decision to submit the study for publication.

Conflicts of interest Dr. León received lecture grants from Merck, Astellas, Gilead, and Pfizer. There are no conflicts of interest for the remaining authors.

\section{Appendix}

Members of the CAVA II Study Group (participating centers in parenthesis): A. Blanco, E. Campos, L. Viña, and M.A. Álvarez Fernández (Hospital Universitario Central de Asturias, Oviedo); C. León, C. Castro, A. Loza, A. Ubeda, J.C. Palomares, E. Martín, T. González, and M. Parra (Hospital Universitario de Valme, Sevilla); V. Jerez and J.D. Jiménez (Complejo Hospitalario Infanta Cristina, Badajoz); J. Ballús, F. Esteve, and J. Ayats (Hospital Universitari de Bellvitge, L'Hospitalet de Llobregat, Barcelona); L. Álvarez, M. Solla, D. Velasco, L. Vizcaíno, T. Rey, and F. Álvarez (Complejo Hospitalario Universitario A Coruña, A Coruña); A. Utande, V. González, A. Tejada, A. Rezusta, and M.J. Revillo (Hospital Universitario Miguel Servet, Zaragoza); A. Zabalegui, M.J. López, L. Llata, M.P. Ortega, and E. Ojeda (Hospital General Yagüe, Burgos); F.J. González and E. Cuchi (Hospital Mutua de Terrassa, Terrassa, Barcelona); M.A. Blasco, R. Diaz, F. del Nogal, M.S. Cuétara, and I. Wilhelmi (Hospital Severo Ochoa, Leganés, Madrid); M. Nieto, P. Merino, Diego A. Rodríguez Serrano, and F. Martínez Sagasti (Hospital Clínico, Madrid); M. J. Broch, M.A. García, V. López J. Prat, and R. Escoms (Hospital de Sagunto, Sagunto, Valencia); L. Tamayo, J.I. Alonso, Z. Franzon, M.A. García Castro, and M.L. Jaime (Complejo Hospitalario de Palencia, Palencia); F. Martín, A. Bueno, R.M. de La Casa, and M. Ruiz Velasco (Clínica Moncloa, Madrid); J. Machado, J. La Rosa, and C. Carazo (Hospital General de Jaén, Jaén), S. Ruiz-Santana, M.A. Hernández, N. Ojeda, O. Fariñas, and A. Bordes (Hospital Universitario Dr. Negrín, Las Palmas 
de Gran Canaria); B. Álvarez (Hospital General Universitario de Alicante, Alicante); A. Martínez, C. Llamas, and J. Ruiz (Hospital Virgen de la Arrixaca, Murcia); and
G. González, A. Renedo, C. Rita, and R. Blázquez (Hospital General Universitario Morales Meseguer, Murcia), Spain.

\section{References}

1. Eggimann P, Bille J, Marchetti O (2011) Diagnosis of invasive candidiasis in the ICU. Ann Intensive Care 1:37. doi:10.1186/2110-5820-1-37

2. León C, Ruiz-Santana S, Saavedra P, Almirante B, Nolla-Salas J, AlvarezLerma F, Garnacho-Montero J, León MA (2006) A bedside scoring system ("Candida score") for early antifungal treatment in non-neutropenic critically ill patients with Candida colonization. Crit Care Med 34:730-737

3. Ostrosky-Zeichner L, Sable C, Sobel J, Alexander BD, Donowitz G, Kan V, Kauffman CA, Kett D, Larsen RA Morrison V, Nucci M, Pappas PG, Bradley ME, Major S, Zimmer L, Wallace D, Dismukes WE, Rex JH (2007) Multicenter retrospective development and validation of a clinical prediction rule for nosocomial invasive candidiasis in the intensive care setting. Eur J Clin Microbiol Infect Dis 26:271-276

4. León C, Ruiz-Santana S, Saavedra P, Galván B, Blanco A, Castro C, Balasini C, Utande-Vázquez A, González de Molina FJ, Blasco-Navalproto MA, López MJ, Charles PE, Martín E, Hernández-Viera MA (2009) Usefulness of the "Candida score" for discriminating between Candida colonization and invasive candidiasis in non-neutropenic critically ill patients: a prospective multicenter study. Crit Care Med 37:1624-1633

5. Kratzer C, Graninger W, Lassnigg A, Presterl E (2011) Design and use of Candida scores at the intensive care unit. Mycoses 54:467-474

6. Koo S, Bryar JM, Page JH, Baden LR, Marty FM (2009) Diagnostic performance of the $(1 \rightarrow 3)$-beta-Dglucan assay for invasive fungal disease. Clin Infect Dis 49:1650-1659

7. Karageorgopoulos DE, Vouloumanou EK, Ntziora F, Michalopoulos A, Rafailidis PI, Falagas ME (2011) $\beta$-D-Glucan assay for the diagnosis of invasive fungal infections: a metaanalysis. Clin Infect Dis 52:750-770
8. Moragues MD, Ortiz N, Iruretagoyena JR, García-Ruiz JC, Amutio E, Rojas A, Mendoza J, Quindós G, Pontón-San Emeterio J (2004) Evaluation of a new commercial test (Candida albicans IFA $\mathrm{IgG}$ ) for the serodiagnosis of invasive candidiasis. Enferm Infecc Microbiol Clin 22:83-88

9. Zaragoza R, Pemán J, Quindós G, Iruretagoyena JR, Cuétara MS, Ramírez P, Gómez MD, Camarena JJ, Viudes A, Pontón J (2009) Clinical significance of the detection of Candida albicans germ tube-specific antibodies in critically ill patients. Clin Microbiol Infect 15:592-595

10. Pemán J, Zaragoza R, Quindós R, Alkorta M, Cuétara MS, Camarena JJ, Ramírez P, Giménez MJ, MartínMazuelos E, Linares-Sicilia MJ, Pontón J (2011) Clinical factors associated with a Candida albicans germ tube antibody positive test in intensive care unit patients. BMC Infect Dis 11:60. doi: 10.1186/1471-2334-11-60

11. Povoa PR, Teixeira-Pinto AM, Carneiro AH (2011) C-reactive protein, an early marker of community-acquired sepsis resolution: a multi-center prospective observational study. Crit Care 15:R169

12. Charles PE, Castro C, Ruiz-Santana S, León C, Saavedra P, Martín E (2009) Serum procalcitonin levels in critically ill patients colonized with Candida spp: new clues for the early recognition of invasive candidiasis? Intensive Care Med 35:2146-2150

13. Schuetz P, Albrich W, Mueller B (2011) Procalcitonin for diagnosis of infection and guide to antibiotic decisions: past, present and future. BMC Med 9:107. doi: 10.1186/1741-7015-9-107

14. Charles PE, Dalle F, Aube H, Doise JM, Quenot JP, Aho LS, Chavanet P, Blettery B (2005) Candida spp. colonization significance in critically ill medical patients: a prospective study. Intensive Care Med 31:393-400

15. León C, Alvarez-Lerma F, RuizSantana S, León MA, Nolla J, Jordá R, Saavedra P, Palomar M (2009) Fungal colonization and/or infection in nonneutropenic critically ill patients: results of the EPCAN observational study. Eur J Clin Microbiol Infect Dis 28:233-242
16. De Pauw B, Walsh TJ, Donnelly JP, Stevens DA, Edwards JE, Calandra T, Pappas PG, Maertens J, Lortholary O, Kauffman CA, Denning DW, Patterson TF, Maschmeyer G, Bille J, Dismukes WE, Herbrecht R, Hope WW, Kibbler CC, Kullberg BJ, Marr KA, Muñoz P, Odds FC, Perfect JR, Restrepo A, Ruhnke M, Segal BH, Sobel JD, Sorrell TC, Viscoli C, Wingard JR, Zaoutis T, Bennett JE (2008) Revised definitions of invasive fungal disease from the European Organization for Research and Treatment of Cancer/Invasive Fungal Infections Cooperative Group and the National Institute of Allergy and Infectious Diseases Mycoses Study Group (EORTC/MSG) Consensus Group. Clin Infect Dis 46:1813-1822

17. Blot SI, Vandewoude KH, De Waele JJ (2007) Candida peritonitis. Curr Opin Crit Care 13:195-199

18. Oude Lashof AM, Rothova A, Sobel JD, Ruhnke M, Pappas PG, Viscoli C, Schlamm HT, Oborska IT, Rex JH, Kullberg BJ (2011) Ocular manifestations of candidemia. Clin Infect Dis 53:262-268

19. Mermel LA, Allon M, Bouza E, Craven DE, Flynn P, O'Grady NP, Raad II, Rijnders BJ, Sherertz RJ, Warren DK (2009) Clinical practice guidelines for the diagnosis and management of intravascular catheter-related infection: 2009 update by the Infectious Diseases Society of America. Clin Infect Dis 49:1-45

20. Breiman L, Freidman JH, Olshen RA, Stone CJ (1984) Classification and regression trees. Wadsworth, Belmont

21. Digby J, Kalbfleisch J, Glenn A, Larsen A, Browder W, Williams D (2003) Serum glucan levels are not specific for presence of fungal infections in intensive care unit patients. Clin Diagn Lab Immunol 10:882-885

22. Takesue Y, Kakehashi M, Ohge H, Imamura Y, Murakami Y, Sasaki M, Morifuji M, Yokoyama Y, Kouyama M, Yokoyama T, Sueda T (2004) Combined assessment of beta-D-glucan and degree of Candida colonization before starting empiric therapy for candidiasis in surgical patients. World $\mathbf{J}$ Surg 28:625-630 
23. Acosta J, Catalan M, Del Palacio-PerézMedel A, Lora D, Montejo JC, Cuetara MS, Moragues MD, Ponton J, del Palacio A (2011) A prospective comparison of galactomannan in bronchoalveolar lavage fluid for the diagnosis of pulmonary invasive aspergillosis in medical patients under intensive care: comparison with the diagnostic performance of galactomannan and of $(1 \rightarrow 3)-\beta$-Dglucan chromogenic assay in serum samples. Clin Microbiol Infect 17:1053-1060

24. Posteraro B, De Pascale G, Tumbarello M, Torelli R, Pennisi MA, Bello G, Maviglia R, Fadda G, Sanguinetti M, Antonelli M (2011) Early diagnosis of candidemia in intensive care unit patients with sepsis: a prospective comparison of $(1 \rightarrow 3)$-beta-D-glucan assay, Candida score, and colonization index. Crit Care 15:R249. doi: 10.1186/cc10507

25. Mohr JF, Sims Ch, Paetznick V, Rodriguez J, Finkelman MA, Rex JH, Ostrosky-Zeichner L (2011) A prospective survey of $(1 \rightarrow 3)$ - $\beta$-Dglucan and its relationship to invasive candidiasis in the surgical ICU setting. J Clin Microbiol 49:58-61
26. Onishi A, Sugiyama D, Kogata Y, Saegusa J, Sugimoto T, Kawano S, Morinobu A, Nishimura K, Kumagai S (2012) Diagnostic accuracy of serum 1,3- $\beta$-D-glucan for Pneumocystis jirovecii pneumonia, invasive candidiasis and invasive aspergillosis: systematic review and meta-analysis. J Clin Microbiol 50:7-15

27. Albert O, Toubas D, Strady C, Cousson J, Delmas C, Vernet V, Villena I (2011) Reactivity of $(1 \rightarrow 3)$ - $\beta$-D-glucan assay in bacterial bloodstream infections. Eur J Clin Microbiol Infect 30:1453-1460

28. Metan G, Agkus C, Nedret Koc A, Elmali F, Finkelman MA (2011) Does ampicillin-sulbactam cause false positivity of $(1,3)$-beta-D-glucan assay? A prospective evaluation of 15 patients without invasive fungal infections. Mycoses. doi: 10.1111/j.1439-0507.2011.02131.x

29. Pickering JW, Sant HW, Bowles CA, Roberts WL, Woods GL (2005)

Evaluation of a $(1 \rightarrow 3)$-beta-D-glucan assay for diagnosis of invasive fungal infections. J Clin Microbiol 43:5957-5962
30. Presterl E, Parschalk B, Bauer E, Lassnigg A, Hajdu S, Graninger W (2009) Invasive fungal infections and (1,3)-beta-D-glucan serum concentrations in long-term intensive care patients. Int $\mathbf{J}$ Infect Dis 13:707-1712

31. Nguyen MH, Wissel MC, Shields RK, Salomoni MA, Hao B, Press EG, Shields RM, Cheng S, Mitsani D, Vadnerkar A, Silveira FP, Kleiboeker SB, Clancy CJ (2012) Performance of Candida real-time polymerase chain reaction, $\beta$-D-glucan assay, and blood cultures in the diagnosis of invasive candidiasis. Clin Infect Dis 54:1240-1248 